\title{
Long-term functional improvements in the 2-year treatment of schizophrenia outpatients with olanzapine long-acting injection
}

This article was published in the following Dove Press journal:

Neuropsychiatric Disease and Treatment

20 June 2014

Number of times this article has been viewed

\author{
Haya Ascher-Svanum' \\ Diego Novick ${ }^{2,3}$ \\ Josep Maria Haro 4 \\ Jordan Bertsch ${ }^{4}$ \\ David McDonnell' \\ Holland Detke'
}

'Eli Lilly and Company, Indianapolis, IN, USA; ${ }^{2}$ Eli Lilly and Company, Windlesham, Surrey, UK;

${ }^{3}$ Departament de Psiquiatria, Universitat Autonoma de Barcelona, Spain; ${ }^{4}$ Parc Sanitari Sant Joan de Déu, Centro de Investigación Biomédica en Red en el Área de Salud Mental, Universitat de Barcelona, Barcelona, Spain
Correspondence: Haya Ascher-Svanum Lilly Corporate Center, DC 2246, Eli Lilly and Company, Indianapolis, IN 46285, USA Tel + I 3172778713

Fax + I 3172767100

Email ascher-svanum_haya@lilly.com
Background: Little is known about the long-term changes in the functioning of schizophrenia patients receiving maintenance therapy with olanzapine long-acting injection (LAI), and whether observed changes differ from those seen with oral olanzapine.

Methods: This study describes changes in the levels of functioning among outpatients with schizophrenia treated with olanzapine-LAI compared with oral olanzapine over 2 years. This was a secondary analysis of data from a multicenter, randomized, open-label, 2-year study comparing the long-term treatment effectiveness of monthly olanzapine-LAI ( $405 \mathrm{mg} / 4$ weeks; $\mathrm{n}=264$ ) with daily oral olanzapine ( $10 \mathrm{mg} /$ day; $\mathrm{n}=260)$. Levels of functioning were assessed with the Heinrichs-Carpenter Quality of Life Scale. Functional status was also classified as "good", "moderate", or "poor", using a previous data-driven approach. Changes in functional levels were assessed with McNemar's test and comparisons between olanzapine-LAI and oral olanzapine employed the Student's $t$-test.

Results: Over the 2-year study, the patients treated with olanzapine-LAI improved their level of functioning (per Quality of Life total score) from 64.0-70.8 $(P<0.001)$. Patients on oral olanzapine also increased their level of functioning from 62.1-70.1 $(P<0.001)$. At baseline, $19.2 \%$ of the olanzapine-LAI-treated patients had a "good" level of functioning, which increased to $27.5 \%(P<0.05)$. The figures for oral olanzapine were $14.2 \%$ and $24.5 \%$, respectively $(P<0.001)$. Results did not significantly differ between olanzapine-LAI and oral olanzapine.

Conclusion: In this 2-year, open-label, randomized study of olanzapine-LAI, outpatients with schizophrenia maintained or improved their favorable baseline level of functioning over time. Results did not significantly differ between olanzapine-LAI and oral olanzapine.

Keywords: antipsychotics, functioning, olanzapine long-acting injection, quality of life, schizophrenia

\section{Introduction}

Schizophrenia is often a chronic and severe illness characterized by impairment in thinking, feeling, and behavior; it is accompanied by impaired functioning, low levels of productivity, and high rates of unemployment. ${ }^{1,2}$ According to the consensus guidelines for the treatment of patients with schizophrenia, antipsychotics are the cornerstone in the treatment of the illness; maximizing patient quality of life and adaptive functioning are the primary treatment goals..$^{3-7}$

Prior antipsychotic research has shown that olanzapine in an oral tablet formulation is associated with favorable functional improvements in the acute and maintenance treatment of patients with schizophrenia. ${ }^{8-11}$ Olanzapine is also available in long-acting injection formulation (LAI, depot), which was shown to significantly improve patient 
level of functioning compared with placebo in an 8-week, acute-phase study of schizophrenia. ${ }^{12}$ Practice guidelines for schizophrenia management recommend depot antipsychotics for patients who are nonadherent with their medication. ${ }^{4} \mathrm{Up}$ to one-third of outpatients are reported to be nonadherent, and another third are reported to be only partially adherent. ${ }^{13}$ Furthermore, patient adherence has been found to deteriorate over time, with up to three-fourths of patients demonstrating only partial adherence after 2 years of treatment. ${ }^{14}$ Medication adherence has been previously shown to predict relapse and hospitalization, ${ }^{15}$ which tend to signal patients' growing difficulties to function in the community. ${ }^{16}$

Although there is evidence supporting the effectiveness of olanzapine-LAI ${ }^{17,18}$ and the associated short-term improvements in patient functioning and quality of life, ${ }^{12}$ little is known about long-term changes in the level of functioning in schizophrenia patients receiving maintenance therapy with olanzapine-LAI, and whether observed changes differ from those seen with oral olanzapine.

The primary objective of the present analysis was to describe the changes in the level of functioning among schizophrenia patients receiving long-term maintenance therapy with olanzapine-LAI, using data from a 2-year, randomized, open-label maintenance study of outpatients with schizophrenia that compared monthly olanzapine-LAI therapy with daily oral olanzapine therapy. As a secondary objective of this analysis, observed functional changes were compared between patients treated with olanzapine-LAI or oral olanzapine.

\section{Materials and methods Study design and participants}

This was a secondary analysis of data from a multicenter, randomized, open-label, 2-year study comparing the longterm treatment effectiveness and safety of olanzapine-LAI with that of daily oral olanzapine in schizophrenia outpatients (ClinicalTrials.gov registration number: NCT00320489; code: F1D-MC-HGLQ). ${ }^{19}$

Participants were aged 18-65 years, with a Diagnostic and Statistical Manual of Mental Disorders, Fourth Edition or Fourth Edition-Text Revision diagnosis of schizophrenia, with a Positive and Negative Syndrome Scale (PANSS) total score $<70$ and a Clinical Global Impression-Severity (CGI-S) scale rating of $\leq 4$, who had not been hospitalized in the 8 weeks before study inclusion, and who were at risk for relapse as demonstrated by at least two episodes of clinical worsening in the past 24 months (2 years) (ie, the patient was hospitalized or required an increased level of care surrounding the episode). Exclusion criteria included: significant suicidal or homicidal risk; pregnancy or breastfeeding; acute, serious, or unstable medical conditions; or substance dependence (except nicotine or caffeine) within the past month.

The study design consisted of two periods - a screening phase during which the patients were screened for eligibility (in visit one and in visit two) and an open-label treatment phase lasting up to 104 weeks. Patients were randomly assigned in a $1: 1$ ratio to receive olanzapine-LAI (405 mg/4 weeks, $\mathrm{n}=264$ ) or oral olanzapine (10 mg/day, $\mathrm{n}=260$ ). Dosing was flexible following the initial randomization dose (150-405 mg/4 weeks for olanzapine-LAI, and 5-20 mg/day for oral olanzapine).

No oral antipsychotic supplementation was allowed after week 8 . Concomitant medications with primarily central nervous system activity were prohibited, except for benzodiazepines and sedative-hypnotics as sleep aids ( $\leq 2 \mathrm{mg} /$ day lorazepam equivalents) and any antidepressants that the patient was already taking (except for fluvoxamine, which was prohibited).

The study protocol was approved by institutional review boards at each site. After receiving a complete description of the study, all patients and/or their authorized legal representatives provided written informed consent before participation.

\section{Measures}

Level of functioning was measured with the HeinrichsCarpenter Quality of Life Scale (QLS). ${ }^{20}$ The QLS is a clinician-rated scale used to assess the impact of schizophrenia on occupational, social, and psychological functioning in patients with schizophrenia. The scale consists of 21 items rated on a 7-point scale from normal or unimpaired functioning (scores of 5 or 6 ) to impaired functioning (scores of 0 and 1). The QLS items assess four domains: intrapsychic foundation; interpersonal relations; instrumental role; and common objects and activities. The QLS scale was administered at baseline, at 22 weeks, at 46 weeks, and at 70 weeks thereafter and at endpoint (104 weeks or at the discontinuation visit). Patient functioning was also classified using cut-off points developed using the QLS. ${ }^{21}$ Patients were considered to have: a "good" level of functioning if the QLS total score was $\geq 84.5$; a "moderate" level if the QLS total score was $<84.5$, and the QLS Intrapsychic foundation score was $\geq 15.5$; and a "poor" level of functioning if the QLS total score was $<84.5$ and the QLS intrapsychic foundation score was $<15.5$. In addition to levels of functioning, symptom 
Table I Baseline sociodemographic and clinical characteristics, by treatment

\begin{tabular}{llll}
\hline Characteristic & Olanzapine-LAI & Olanzapine & $\boldsymbol{P}^{\mathbf{a}}$ \\
\hline Number of patients & $(\mathrm{n}=264)$ & $(\mathrm{n}=260)$ & $83(31.9)$ \\
Female, $\mathrm{n}(\%)$ & $89(33.7)$ & $40.1(10.8)$ & 0.66 \\
Age at study entry (years), mean (SD) & $41.7(10.9)$ & $26.5(8.7)$ & 0.09 \\
Age at onset (years), mean (SD) & $25.9(9.2)$ & $3.3(0.7)$ & 0.28 \\
CGI-S score, mean (SD) & $3.2(0.8)$ & $56.6(8.7)$ & 0.82 \\
PANSS total score, mean (SD) & $56.7(9.8)$ & $48(18.5)$ & 0.43 \\
In paid employment, $\mathrm{n}(\%)$ & $56(21.3)$ & $56(21.6)$ & 0.43 \\
Living independently, $\mathrm{n}(\%)$ & $67(25.5)$ & & 0.29 \\
\hline
\end{tabular}

Note: ${ }^{P}$-value comparing olanzapine-LAI with oral olanzapine.

Abbreviations: LAI, long-acting injection; SD, standard deviation; CGI-S, Clinical Global Impression-Severity; PANSS, Positive and Negative Symptom Scale.

severity was assessed using the 30 -item PANSS $^{22}$ and the CGI-S scale. ${ }^{23}$

\section{Statistical methods}

The patients included in the analyses were those randomized patients with at least one postbaseline assessment; the last observation carried forward methodology was employed. A total of 524 patients were included; 264 (50.4\%) received olanzapine-LAI, and 260 (49.6\%) received oral olanzapine. Changes in the level of functioning from baseline during the study were assessed with McNemar's test, and comparisons between olanzapine-LAI and oral olanzapine on level of functioning per QLS total score employed the Student's $t$-test. All analyses were performed using SAS, version 9.1 (SAS Institute Inc., Cary, NC, USA).

\section{Results}

The baseline sociodemographic and clinical characteristics of the patients in the two treatment groups are shown in Table 1. There were no significant differences between the
olanzapine-LAI and the oral olanzapine groups. About one-third of the patients in both groups were women. Mean age at study entry was about 41 years, and the mean time since the onset of schizophrenia was about 26 years. Baseline illness severity was within the mild range and similar across the two groups; the mean CGI-S score was 3.2 for olanzapine-LAI and 3.3 for oral olanzapine, indicating that these patients were mildly ill. Similarly, the total PANSS scores were about 57 for both groups, a score consistent with being mildly ill with regard to symptomatology. ${ }^{24}$ Roughly $20 \%$ of the patients were unemployed, and about one-fourth were living independently. There were no group differences in the proportion of patients who discontinued before the end of the study.

Over the 2-year study, patients treated with olanzapineLAI improved their level of functioning (QLS total score) from a mean of 64.0-70.8 $(P<0.001)$ (Table 2). Patients taking oral olanzapine increased their QLS total score from 62.1-70.1 $(P<0.001)$.

At baseline, $19.2 \%$ of the olanzapine LAI-treated patients were identified as having a "good" level of functioning,

Table 2 Change in level of functioning per QLS total and QLS subscale scores from baseline to last observation, by treatment group

\begin{tabular}{|c|c|c|c|c|}
\hline QLS score/visit & Olanzapine-LAI ${ }^{\mathrm{a}}$ & $P^{b}$ & Oral olanzapine & $P^{b}$ \\
\hline \multicolumn{5}{|c|}{ QLS total score, mean (SD) } \\
\hline Baseline & $64.0(21.2)$ & $<0.001$ & $62.1(18.8)$ & $<0.001$ \\
\hline Last observation years & $70.8(22.9)$ & & $70.1(22.4)$ & \\
\hline \multicolumn{5}{|c|}{ QLS common objects and activities, mean (SD) } \\
\hline Baseline & $6.6(2.6)$ & $<0.001$ & $6.5(2.5)$ & $<0.001$ \\
\hline Last observation & $7.3(2.6)$ & & $7.1(2.6)$ & \\
\hline \multicolumn{5}{|c|}{ QLS intrapsychic foundation, mean (SD) } \\
\hline Baseline & $21.9(7.9)$ & $<0.001$ & $21.6(6.9)$ & $<0.001$ \\
\hline Last observation & $24.1(8.7)$ & & $23.9(8.4)$ & \\
\hline \multicolumn{5}{|c|}{ QLS intrapersonal relation, mean (SD) } \\
\hline Baseline & $21.0(10.0)$ & $<0.001$ & $20.0(9.3)$ & $<0.001$ \\
\hline Last observation & $24.2(10.2)$ & & $23.9(10.0)$ & \\
\hline \multicolumn{5}{|c|}{ QLS instrumental role, mean (SD) } \\
\hline Baseline & I4.I (3.6) & $<0.001$ & $13.9(3.2)$ & $<0.001$ \\
\hline 2 years & $14.8(3.9)$ & & I4.8 (3.8) & \\
\hline
\end{tabular}

Notes: ${ }^{2}$ There were no statistical differences between olanzapine-LAl and oral olanzapine in any of the ratings. ${ }^{\mathrm{P} P}$ value; change from baseline to endpoint. Abbreviations: LAI, long-acting injection; SD, standard deviation; QLS, Quality of Life Scale. 
Table 3 Proportion of patients with "good", "moderate", and "poor" levels of functioning at baseline and last observation, by treatment group

\begin{tabular}{|c|c|c|c|c|}
\hline Visit/functioning cluster & Olanzapine-LAI & Oral olanzapine & Total & $P^{a}$ \\
\hline Baseline, n (\%) & & & & $\overline{0.11}$ \\
\hline "Good" & $50(19.2)$ & $37(14.2)$ & 87 & \\
\hline "Moderate" & $150(57.5)$ & $172(66.2)$ & 322 & \\
\hline "Poor" & $61(23.4)$ & $51(19.6)$ & 112 & \\
\hline 2 years, $n(\%)$ & & & & 0.26 \\
\hline "Good" & $66(27.5)$ & $56(24.5)$ & 122 & \\
\hline "Moderate" & $125(52.1)$ & $136(59.4)$ & 261 & \\
\hline “Poor” & $49(20.4)$ & $37(16.2)$ & 86 & \\
\hline
\end{tabular}

Note: ${ }^{a}$ value comparing the proportion of patients in each cluster between olanzapine-LAl and oral olanzapine.

Abbreviation: LAl, long-acting injection.

which increased to $27.5 \%$ following up to 2 years of therapy (Table 3). There was a numerical, but not a statistically significant, decrease in the proportion of patients with a "moderate" level of functioning (from 57.5\%-52.1\%) and in the proportion of patients with a "poor" level of functioning (from 23.4\%-20.4\%). Results were not significantly different between the oral olanzapine and the olanzapine-LAI treatment groups.

Baseline characteristics of the patients in the "good", "moderate", and "poor" functional clusters are shown in Table 4. There were significant differences between the groups for CGI-S score, PANSS total score, and functioning parameters, but not between the groups in the proportion of females, age at study entry, and time since illness onset.

The proportion of patients in the "good", "moderate", and "poor" functioning clusters at endpoint, by their baseline functional cluster and treatment group, are shown in Table 5. Although there was some variability within each group, there was a consistent trend toward an increase in the proportion of patients in the "good" functioning cluster.

\section{Discussion}

In this 2-year, randomized, open-label maintenance study, schizophrenia patients who were treated with olanzapine-LAI experienced a significant improvement in their level of functioning over time. The improvements were observed in the total QLS score and in each of its four functional domains: interpersonal; instrumental (occupational); intrapsychic (motivational); and in common objects and activities (a domain that may reflect a patient's ability to function in the community). Moreover, when using the functional categories of "good", "moderate", and "poor" to assess change in functional levels, most patients (73.5\%-76.1\%) maintained their "good" baseline level of functioning, and some moved from "moderate" and "poor" to the "good" functional category. More specifically, of the patients treated with olanzapineLAI, 18.8\% moved from "moderate" to "good" levels of functioning and $9.1 \%$ moved from "poor" to "good". Of patients treated with oral olanzapine, a similar proportion of patients moved from "moderate" to "good" levels of functioning (19.6\%) but a numerically smaller proportion (2.4\%) moved from "poor" to "good". Overall, the observed improvements in QLS scores and in the proportion of patients in the "good" functional category did not differ significantly between patients treated with monthly olanzapine-LAI and daily oral olanzapine.

The current assessment of levels of functioning in the long-term maintenance study of patients with schizophrenia

Table 4 Baseline characteristics of the patients in the "good", "moderate", and "poor" functional clusters (all patients, n=524)

\begin{tabular}{|c|c|c|c|c|}
\hline \multirow[t]{2}{*}{ Characteristic } & \multicolumn{3}{|c|}{ Functioning cluster } & \multirow[t]{2}{*}{$P^{a}$} \\
\hline & "Good" & "Moderate" & "Poor" & \\
\hline Number of patients & $(n=87)$ & $(n=322)$ & $(n=|| 2)$ & \\
\hline Female, n (\%) & $33(38)$ & $102(32)$ & $36(32)$ & 0.5367 \\
\hline Age at study entry (years), mean (SD) & $39.2(11.4)$ & $40.8(10.7)$ & $42.7(10.9)$ & 0.0928 \\
\hline Time since onset (years), mean (SD) & $13.9(11.2)$ & $14.6(10.2)$ & $15.8(10.7)$ & 0.2367 \\
\hline CGI-S score, mean (SD) & $2.7(0.9)$ & $3.3(0.7)$ & $3.5(0.6)$ & $<0.0001$ \\
\hline PANSS total score, mean (SD) & $50.0(10.5)$ & $57.1(8.4)$ & $60.3(7.9)$ & $<0.000$ I \\
\hline In paid employment, n (\%) & $39(45)$ & $59(18)$ & $6(5)$ & $<0.0001$ \\
\hline Living independently, n (\%) & $25(29)$ & $84(26)$ & $13(12)$ & 0.0032 \\
\hline
\end{tabular}

Note: ${ }^{a} P$ value comparing the three clusters.

Abbreviations: SD, standard deviation; CGI-S, Clinical Global Impression-Severity; PANSS, Positive and Negative Symptom Scale. 
Table 5 Proportion of patients in the "good", "moderate", and "poor" functioning clusters at last observation, by baseline functional cluster and treatment group

\begin{tabular}{|c|c|c|c|c|}
\hline \multirow{2}{*}{$\begin{array}{l}\text { Treatment/functioning cluster } \\
\text { at baseline }\end{array}$} & \multicolumn{3}{|c|}{ Functioning cluster at endpoint } & \multirow[t]{2}{*}{ Total, $r$} \\
\hline & "Good" & "Moderate" & “Poor" & \\
\hline \multicolumn{5}{|l|}{ Olanzapine-LAI, n (\%) } \\
\hline "Good" & $35(76.1)$ & II (23.9) & $0(0.0)$ & 46 \\
\hline "Moderate" & $26(18.8)$ & $93(67.4)$ & $19(13.8)$ & 138 \\
\hline "Poor" & $5(9.1)$ & $20(36.4)$ & $30(54.5)$ & 55 \\
\hline Total, n (\%) & $66(27.6)$ & $124(5 \mid .9)$ & $49(20.5)$ & 239 \\
\hline \multicolumn{5}{|l|}{ Oral olanzapine, n (\%) } \\
\hline "Good" & $25(73.5)$ & $8(23.5)$ & I (2.9) & 34 \\
\hline "Moderate" & $30(19.6)$ & 110 (7I.9) & $13(8.5)$ & 153 \\
\hline “Poor” & I (2.4) & $18(42.9)$ & $23(54.8)$ & 42 \\
\hline Total, n (\%) & $56(24.5)$ & $136(59.4)$ & $37(16.2)$ & 229 \\
\hline
\end{tabular}

Notes: There were no statistical differences between the change from baseline to endpoint for each of the functioning clusters when comparing olanzapine-LAl and oral olanzapine. Percentages may not $=100$, due to rounding.

Abbreviation: LAI, long-acting injection.

provides valuable information for patients, clinicians, and other health care decision makers about the value of antipsychotic therapy, and - specifically - about olanzapine therapy in depot or oral formulations, to enhance the patients' functional status, and thus their potential ability to achieve greater reintegration into society. While antipsychotic medications play an important role in achieving this goal, it appears that a patient's level of functioning depends on a host of factors, including his or her symptom severity level, various social and environmental factors, ${ }^{25,26}$ and the level of cognitive deficits. ${ }^{27}$

Our findings are consistent with a previous study showing that patients receiving another long-acting atypical antipsychotic (risperidone-LAI) also experience improvements in functioning over the course of maintenance treatment, although our findings apply to a longer period of time ${ }^{28,29}$ and provide a relevant comparison group (the oral counterpart of the depot formulation) that is typically missing from prior research efforts.

\section{Limitations}

Current findings need to be evaluated in the context of the study limitations. First, the present study included a patient population that was clinically stable on oral olanzapine at baseline, manifested a relative low level of symptom severity, and had a substantial proportion of patients whose level of functioning was deemed to be "good". These relatively favorable baseline patient characteristics may have created a ceiling effect that curtailed the ability to find marked improvements from baseline and may have also reduced the ability to differentiate between the two treatment groups. Second, as with other randomized clinical trials of schizophrenia patients, ${ }^{30}$ this randomized trial included mostly adherent patients. In such an adherent patient population, it is difficult to differentiate between oral and depot therapy, although differences between these formulations are likely to manifest in real world practice where long-acting injections are often reserved for nonadherent patients. Third, in this study, the highest possible dose of olanzapine-LAI was $405 \mathrm{mg} / 4$ weeks, which is comparable to $15 \mathrm{mg} /$ day of oral olanzapine. However, patients randomized to oral olanzapine could receive a higher dose - up to $20 \mathrm{mg}$ /day. Therefore, it is possible that patients treated with oral olanzapine (but not patients treated with olanzapine-LAI) could be rescued with a higher dose of the medication, if needed. Thus, although the two treatment groups did not differ significantly on functional outcomes, the difference in the maximum daily dose may have placed the olanzapine-LAI treatment group at a relative disadvantage to oral olanzapine. Last, level of functioning was assessed only at five points of time over the 2-year study. This prevented the ability to describe the detailed course of change in level of functioning over time. ${ }^{19}$

\section{Conclusion}

In this 2-year open-label, randomized study of patients with schizophrenia treated with olanzapine-LAI, most patients either maintained their favorable baseline level of functioning or further improved it over time. Although results did not differ significantly between the olanzapine-LAI and the oral olanzapine treatment groups, the lack of differentiation may have been driven by the fact that most patients who enrolled in this study were adherent and mildly ill, and are not patients who are typically treated with depot antipsychotics in usual care. 


\section{Author contributions}

All of the authors contributed to the design of the analysis of the study. All authors were involved in the interpretation of data. Jordan Bertsch and Josep Maria Haro conducted the statistical analysis. All authors contributed to development of the manuscript, revised it critically for important intellectual content, and gave their approval of this version to be published.

\section{Acknowledgments}

The authors thank all the investigators and patients who participated in this study, and Sarah Smith, PhD, for editorial assistance.

\section{Disclosure}

This study was funded by Eli Lilly and Company. Josep Maria Haro has acted as consultant or speaker for AstraZeneca, Eli Lilly, Lundbeck, and Hoffman-La Roche Ltd; Jordan Bertsch conducted the statistical analysis under a contract of Fundació Sant Joan de Déu with Eli Lilly and Company. Diego Novick, David McDonnell, Holland Detke, and Haya Ascher-Svanum are employees of Eli Lilly and Company. The authors declare no other conflicts of interest in this work.

\section{References}

1. Lenroot R, Bustillo JR, Lauriello J, Keith SJ. Integrated treatment of schizophrenia. Psychiatr Services. 2003;54(11):1499-1507.

2. Turner MS, Stewart DW. Review of the evidence for the long-term efficacy of atypical antipsychotic agents in the treatment of patients with schizophrenia and related psychoses. J Psychopharmacol. 2006; 20(6 Suppl):20-37.

3. Kane JM, Leucht S, Carpenter D, Docherty JP; Expert Consensus Panel for Optimizing Pharmacologic Treatment of Psychotic Disorders, 2003. The expert consensus guideline series. Optimizing pharmacologic treatment of psychotic disorders. Introduction: methods, commentary, and summary. J Clin Psychiatry. 2003;64 Suppl 12:5-19.

4. Lehman AF, Lieberman JA, Dixon LB, et al; American Psychiatric Association; Steering Committee on Practice Guidelines. Practice guideline for the treatment of patients with schizophrenia, second edition. Am J Psychiatry. 2004;161(2 Suppl):1-56.

5. Falkai P, Wobrock T, Lieberman J, et al; WFSBP Task Force on Treatment Guidelines for Schizophrenia. World Federation of Societies of Biological Psychiatry (WFSBP) guidelines for biological treatment of schizophrenia, Part 1: acute treatment of schizophrenia. World J Biol Psychiatry. 2005;6:132-191.

6. Falkai P, Wobrock T, Lieberman J, et al; WFSBP Task Force on Treatment Guidelines for Schizophrenia. World Federation of Societies of Biological Psychiatry (WFSBP) guidelines for biological treatment of schizophrenia, part 2: long-term treatment of schizophrenia. World J Biol Psychiatry. 2006;7(1):5-40.

7. Kreyenbuhl J, Buchanan RW, Dickerson FB, Dixon LB; Schizophrenia Patient Outcomes Research Team (PORT). The Schizophrenia Patient Outcomes Research Team (PORT): updated treatment recommendations 2009. Schizophr Bull. 2010;36(1):94-103.

8. Naber D, Moritz S, Lambert M, et al. Improvement of schizophrenic patients' subjective well-being under atypical antipsychotic drugs. Schizophr Res. 2001;50(1-2):79-88.
9. Haro JM, Edgell ET, Novick D, et al; SOHO advisory board. Effectiveness of antipsychotic treatment for schizophrenia: 6-month results of the Pan-European Schizophrenia Outpatient Health Outcomes (SOHO) study. Acta Psychiatr Scand. 2005;111(3):220-231.

10. Ciudad A, Olivares JM, Bousoño M, Gómez JC, Alvarez E. Improvement in social functioning in outpatients with schizophrenia with prominent negative symptoms treated with olanzapine or risperidone in a 1 year randomized, open-label trial. Prog Neuropsychopharmacol Biol Psychiatry. 2006;30(8):1515-1522.

11. Liu-Seifert H, Ascher-Svanum H, Osuntokun O, Jen KY, Gomez JC. Change in level of productivity in the treatment of schizophrenia with olanzapine or other antipsychotics. BMC Psychiatry. 2011;11:87.

12. Witte MM, Case MG, Schuh KJ, Ascher-Svanum H. Effects of olanzapine long-acting injection on levels of functioning among acutely ill patients with schizophrenia. Curr Med Res Opin. 2012;28(3): 315-323.

13. Masand PS, Roca M, Turner MS, Kane JM. Partial adherence to antipsychotic medication impacts the course of illness in patients with schizophrenia: a review. Prim Care Companion J Clin Psychiatry. 2009;11(4):147-154.

14. Fleischhacker WW, Oehl MA, Hummer M. Factors influencing compliance in schizophrenia patients. J Clin Psychiatry. 2003;64 Suppl 16: $10-13$.

15. Weiden PJ, Kozma C, Grogg A, Locklear J. Partial compliance and risk of rehospitalization among California Medicaid patients with schizophrenia. Psychiatr Serv. 2004;55(8):886-891.

16. Ascher-Svanum H, Faries DE, Zhu B, Ernst FR, Swartz MS, Swanson JW. Medication adherence and long-term functional outcomes in the treatment of schizophrenia in usual care. J Clin Psychiatry. 2006;67(3): 453-460.

17. Lauriello J, Lambert T, Andersen S, Lin D, Taylor CC, McDonnell D. An 8-week, double-blind, randomized, placebo-controlled study of olanzapine long-acting injection in acutely ill patients with schizophrenia. J Clin Psychiatry. 2008;69(5):790-799.

18. Kane JM, Detke HC, Naber D, et al. Olanzapine long-acting injection: a 24-week, randomized, double-blind trial of maintenance treatment in patients with schizophrenia. Am J Psychiatry. 2010;167(2): 181-189.

19. Detke HC, Weiden PJ, Llorca PM, et al. Comparison of olanzapine long-acting injection and oral olanzapine: a 2-year, randomized, openlabel study in outpatients with schizophrenia. J Clin Psychopharmacol. April 28, 2014. [Epub ahead of print].

20. Heinrichs DW, Hanlon TE, Carpenter WT Jr. The Quality of Life Scale: an instrument for rating the schizophrenic deficit syndrome. Schizophr Bull. 1984;10(3):388-398.

21. Ascher-Svanum H, Novick D, Haro JM, Aguado J, Cui Z. Empirically driven definitions of "good," "moderate," and "poor" levels of functioning in the treatment of schizophrenia. Quality of Life Research. 2013;22(8):2085-2094.

22. Kay SR, Fiszbein A, Opler LA. The positive and negative syndrome scale (PANSS) for schizophrenia. Schizophr Bull. 1987;13(2):261-276.

23. Guy W. ECDEU Assessment Manual for Psychopharmacology-Revised. Rockville, MD: US Department of Health, Education, and Welfare; 1976.

24. Leucht S, Kane JM, Kissling W, Hamann J, Etschel E, Engel RR. What does the PANSS mean? Schizophr Res. 2005;79(2-3):231-238.

25. Dan A, Kumar S, Avasthi A, Grover S. A comparative study on quality of life of patients of schizophrenia with and without depression. Psychiatry Res. 2011;189(2):185-189.

26. Ritsner MS, Arbitman M, Lisker A, Ponizovsky AM. Ten-year quality of life outcomes among patients with schizophrenia and schizoaffective disorder II. Predictive value of psychosocial factors. Qual Life Res. 2011;21(6):1075-1084.

27. Mohamed S, Rosenheck R, Swartz M, Stroup S, Lieberman JA, Keefe RS. Relationship of cognition and psychopathology to functional impairment in schizophrenia. Am J Psychiatry. 2008;165(8): 978-987. 
28. de Jong JT, Komproe IH. A 15-year open study on a cohort of West-African out-patients with a chronic psychosis. Soc Psychiatry Psychiatr Epidemiol. 2006;41(11):897-903.

29. Lambert M, De Marinis T, Pfeil J, Naber D, Schreiner A. Establishing remission and good clinical functioning in schizophrenia: predictors of best outcome with long-term risperidone long-acting injectable treatment. Eur Psychiatry. 2010;25(4):220-229.
30. Barnett PG, Scott JY, Rosenheck RA; CSP 555 Study Group. How do clinical trial participants compare to other patients with schizophrenia? Schizophr Res. 2011;130(1-3):34-39.

\section{Publish your work in this journal}

Neuropsychiatric Disease and Treatment is an international, peerreviewed journal of clinical therapeutics and pharmacology focusing on concise rapid reporting of clinical or pre-clinical studies on a range of neuropsychiatric and neurological disorders. This journal is indexed on PubMed Central, the 'PsycINFO' database and CAS, and is the official journal of The International Neuropsychiatric Association (INA). The manuscript management system is completely online and includes a very quick and fair peer-review system, which is all easy to use. Visit http://www.dovepress.com/testimonials.php to read real quotes from published authors.

Submit your manuscript here: http://www.dovepress.com/neuropsychiatric-disease-and-treatment-journal 